\title{
2 \\ UMA NOVA FORMAÇÃO DOCENTE PARA UM VELHO \\ TRABALHO: PRECARIZAÇÃO E ALIGEIRAMENTO*
}

\author{
Leoclécio Dobrovoski Silva Pereira \\ Fabiane Santana Previtali
}

\section{Introdução}

A educação, no seu sentido amplo, está associada à formação do ser social num processo histórico e dinâmico (SAVIANI, 2019). Ela é expressão do metabolismo societal que imiscui o ser humano e a natureza pelo trabalho na produção de conhecimentos materiais e imateriais que se tornam acervo da humanidade e os quais são, fundamentalmente hoje, na sociedade da era informacional e do proletariado digital (ANTUNES, 2018), sistematizados nas instituições educacionais. Não cabe, portanto, analisar as mudanças educacionais independentemente daquelas que se processam no capitalismo em sua fase financeirizada (HARVEY, 2011).

Nesse sentido, a educação institucionalizada não se configura como neutra. Ao contrário, ela se faz cotidianamente em meio a conflitos ideológicos e políticos que trazem em si concepções de mundo e de educação, sobre o quê e como ensinar que, por sua vez, se materializam políticas educacionais, dentre elas a de formação de professores/as para a educação básica. Na perspectiva neoliberal, os/as docentes licenciados/as para o magistério na educação básica são vistos, ao mesmo tempo, como vilões ou heróis da educação na medida em que são individualmente responsabilizados pelo processo educacional, desconsiderando-se os elementos histórico-estruturais mais amplos e sob os quais estão alicerçadas as políticas de formação inicial e continuada de professores/as (SILVA, JR., 2003; HYPOLITO, 2015; PEREIRA, 2018; PREVITALI; FAGIANI, 2017; GATTI, 2019). Assim, tomando por base a análise da Lei de Diretrizes e Base (LDB) 9.394/1996 (BRASIL, 1996), do Conselho Nacional de Educação (BRASIL, 1997, 2015, 2019), dados do INEP (2018) e o debate com a literatura pertinente ao tema, argumenta-se que, se há avanços na legislação no que concerne à formação docente, eles ocorrem em um contexto marcado pelo neoliberalismo e pela Nova Gestão Pública, consubstanciando-se aquém das demandas da categoria docente e da sociedade civil.

Este capítulo está estruturado em duas seções além da introdução e das considerações finais. $\mathrm{Na}$ primeira seção problematiza-se as contribuições, 
avanços e retrocessos que a Lei de Diretrizes e Base (LDB) 9.394/1996 estabeleceu para a formação de profissionais a atuarem na educação básica, capacitação em serviço e formação continuada, em correspondência ao estabelecido pelo Conselho Nacional de Educação (BRASIL, 1997, 2015), com vistas a formação em massa dos profissionais da educação. Na segunda seção apresenta-se a análise da BNC-Formação, dada pela resolução número 2, de dezembro de 2019, segundo a qual se identificam estratégias para a formação dos profissionais da educação. Busca-se demonstrar, por meio de dados do Censup (2018), a prevalência por cursos bacharéis e tecnólogos e o déficit de profissionais da educação. Por fim, são apresentadas as considerações finais do trabalho, indicando a necessidade de maior atenção as demandas da categoria docente quanto ao processo formativo conjugado as melhores condições de trabalho para uma educação, de fato, humanizadora.

\section{LDB e CNE: contradições e desafios para a Formação Docente}

Está em movimento um novo momento da organização capitalista fundada sob o tripé do encolhimento do Estado enquanto regulador da sociabilidade e dos direitos, da expansão da lógica mercadológica-empresarial e da afirmação das propostas neoliberais que levam ao ultra-individualismo. A educação escolar não está imune a essas mudanças, quer seja no plano ideológico, quer seja, na implementação de propostas e reformas educacionais. Cabe a ela (con)formar, no plano técnico e ideológico, a nova classe trabalhadora adequada a responder ao novo patamar sociotécnico do trabalho. Nesse contexto, a escola está em disputa em torno de projetos educacionais que valorizam habilidades técnicas desprovidas de conteúdo teórico-científico, voltadas apenas para o mercado de trabalho e projetos que visam a formação humana humanizadora que deverá atuar de forma responsável e crítica não apenas no mercado de trabalho, mas na preservação da vida em sociedade. No centro dessa disputa ideológica, mas também prática pois se traduz em escolhas concretas, sobre referencial teórico, conteúdos e metodologias, está o/a docente, principal agente do processo formativo escolar (GATTI, 2019). Coloca-se em questão: que formação docente? Nesse contexto, visando ao alcance de metas quantitativas para a educação por um lado e, por outro, reduzir as resistências as novas formas de gestão da força de trabalho, um processo de (trans)formação docente está em curso, considerando-se sua formação inicial, nos cursos de nível superior, as licenciaturas, foco deste artigo, mas também nas relações estabelecidas no processo de trabalho propriamente dito, desenvolvido nas unidades escolares e nas relações laborais. 
A Lei de Diretrizes e Base (LDB) 9.394/1996 (BRASIL, 1996), no que se refere a formação de profissionais para a educação básica no Brasil, vem a calhar com a necessidade de estabelecer parâmetros para qualificar profissionais a atuarem nesta modalidade de ensino "[...] far-se-á em nível superior, em curso de licenciatura plena, admitida, como formação mínima para o exercício do magistério" (BRASIL, 1996, p. 24). Esta medida se deu pela conjuntura dos profissionais que em boa parte não atuavam segundo seu campo de conhecimento específico e com formação em nível superior, situação esta que as diretrizes precedentes não orientavam.

O período de transição para atendimento ao que a lei estabeleceu foi fixado em dez anos e definiu no artigo 63 que aos institutos superiores de educação caberia a formação de profissionais "[...] para a educação infantil e para as primeiras séries do ensino fundamental" formação pedagógica para portadores de diplomas e formação continuada (BRASIL, 1996, p. 25).

Como a LDB (BRASIL, 1996) não estabeleceu carga horária mínima para a formação de professores/as, esta foi definida pelo Conselho Pleno em 2001, em que 400 horas foram direcionadas para o estágio supervisionado, 400 horas para prática de componente curricular, 200 horas para atividades complementares e 1.800 horas para conteúdos curriculares, totalizando 2.800 horas de curso (BRASIL, 2001).

Em face à carência da formação de profissionais docentes e em consonância com a LDB que trata no artigo 87, \$3-III, “[...] realizar programas de capacitação para todos os professores em exercício, utilizando também, para isto, os recursos da educação a distância" (BRASIL, 1996, p. 9), em 1997, no artigo oitavo, o Conselho Nacional de Educação, por meio da resolução número dois, autoriza através de programas de educação à distância, a capacitação em serviço e formação para portadores de diplomas, "[...] a parte teórica do programa poderá ser oferecida utilizando metodologia semipresencial, na modalidade de ensino a distância, sem redução da carga horária prevista [...]" (BRASIL, 1997, p. 9). Dado ao que reza os ajustes para a formação de professores/as pela LDB e CNE, as medidas foram direcionadas para os profissionais que já atuavam no campo educacional, como mecanismo para se adequarem no prazo estabelecido de dez anos, assim como para a formação de novos profissionais.

O Conselho Nacional de Educação (CNE) estabeleceu que a formação em programas especiais, em caráter especial "[...] é destinado a portadores de diploma de nível superior, em cursos relacionados à habilitação pretendida que ofereçam sólida base de conhecimentos na área de estudos ligada a essa habilitação [...]" (BRASIL, 1997, p. 7) está voltada para a formação de disciplinas que integram a educação profissional em nível médio, o ensino médio e as quatro séries finais do ensino fundamental. Às instituições que a 
oferecessem, deveriam obedecer para garantia da qualidade um núcleo básico, núcleo estrutural e núcleo integrador.

Nesse contexto, as instituições de ensino deveriam oferecer programas de formação sólida, conforme a seguinte estrutura: "O programa se desenvolverá em, pelo menos, 540 horas, incluindo a parte teórica e prática, esta com duração mínima de 300 horas" (BRASIL, 1997, p. 8), ficando estabelecidas minimamente 300 horas para o estágio e 240 horas para atividades teóricas, a serem oferecidos por universidades e instituições de ensino superior que tenham cursos de licenciatura nas disciplinas pretendidas.

Importa destacar que este programa de "caráter especial" não estabeleceu uma carga horária diferenciada para formação de profissionais a atuarem no ensino proveniente de cursos não afins. Assim, independentemente de o candidato ter uma formação bacharelada ou em licenciatura, poderiam aderir ao programa. Significa dizer que seja para um profissional do direito, da administração, um teólogo entre outros, assim como para aqueles que já tinham formação em uma licenciatura e queriam transitar em outras áreas de conhecimento, a obrigatoriedade da formação era a mesma. Depreende-se que, dada a complexidade da prática do ensino, tanto a formação oferecida aos já licenciados como aos bacharéis, representa significativo entrave para o ensino com qualidade socialmente referenciada.

Esta situação sofreu alteração por meio da Resolução n. 2 , de $1^{\circ}$ de julho de 2015 (BRASIL, 2015), em que foi definido as Diretrizes Curriculares Nacionais (DCNs) para formação em licenciaturas, formação continuada, formação pedagógica para graduados e segunda licenciatura. Esta resolução estabeleceu que "os cursos de formação pedagógica para graduados não licenciados, de "caráter emergencial e provisório" (BRASIL, 2015, p. 12. grifo nosso), têm por objetivo contribuir para o decréscimo do déficit de profissionais nas áreas específicas da docência.

Para os cursos de formação inicial do magistério da educação básica, ficou estabelecido que: a carga horária mínima seja de 3.200 (três mil e duzentas) horas para as licenciaturas; os cursos de formação pedagógica devem ter de 1.000 (hum mil) a 1.400 (mil e quatrocentas) horas, respectivamente para formação daqueles que tem curso superior na mesma área de origem e para aqueles que têm formação em curso que não seja da mesma área de origem; os cursos de segunda licenciatura devem constar de carga horária mínima variável de 800 (oitocentas) a 1.200 (mil e duzentas) horas, dependendo da equivalência entre a segunda licenciatura e a formação original (BRASIL, 2015).

Destaca-se que nas medidas de "aligeiramento" da formação de professores/as estabelecidas pela pelo Conselho Nacional de Educação em 1997 e em 2015, foram designadas pelas nomenclaturas de programa de "caráter especial" e "caráter emergencial e provisório" respectivamente, ambas 
estabelecidas para suprir déficits de profissionais para atuarem na educação básica, conforme definida pelo próprio Conselho Nacional de Educação no parecer número 4 (quatro) de 1997, segundo o qual vários estados da federação continham números suficientes de formados/as, contudo a questão salarial e as condições de trabalho tornava inviável a atuação desses profissionais, os quais optavam por outros postos mais rentáveis e com melhores condições de execução. Assim, o CNE, (BRASIL, 1997, p. 3), destaca:

Enfatizamos a importância da definição de uma política nacional ampla para a formação profissional de docentes, que trate integradamente a formação inicial, as condições de trabalho, as questões salariais e de carreira e a formação continuada.

Nestes termos, conforme Pereira (2018), apresenta-se um descompasso entre os anseios da categoria docente e suas expectativas concernentes às condições de trabalho e remuneração, os quais são objetos de descaso pelas administrações dos estados, municípios e pelo governo federal, ora pela alegação de incapacidade financeira para o cumprimento do piso salarial e condições adequadas de trabalho, ora por considerar o que estabelece a legislação como letra morta da lei.

Vale destacar que este período é marcado pela ascensão das políticas neoliberais, associadas à reforma do Estado com a adoção dos princípios da Nova Gestão Pública ou Estado Gestor ou ainda Gerencialismo (NEWMAN; CLARKE, 2012; HILL, 2003; OLIVEIRA, 2015; PREVITALI; FAGIANI, 2017, 2020).

Para Clarke e Newman (1997), o gerencialismo compreende um conjunto de elementos culturais e ideológicos que se tornam hegemônicos a partir dos anos 1970, levando ao reordenamento da esfera político-jurídica de regulação social, marcado pelo aparecimento da política da Nova Direita sob o comando de Margaret Thatcher (1979-1992) e John Major (1992-1997) na GrãBretanha e pelo governo de Reagan (1981-1989) nos EUA. Para Previtali e Fagiani $(2017,2020)$, a difusão da NGP cumpre um papel fundamental no processo de (des)regulação social em prol do capital e contra o trabalho na medida em que promove massivamente as privatizações diretas e estimula parcerias com o setor privado, implicando na transferência de recursos públicos para o privado, perdoa e/ou redefini multas e impostos de empresas privadas, reduzindo fundos públicos e, por fim, desregulamenta as relações laborais, reduzindo os custos do trabalho para o capital.

Convém lembrar que a aprovação da lei da educação, LDB (BRASIL, 1996) se deu no primeiro mandato do governo Fernando Henrique Cardoso, em consonância com os princípios e da NGP, o que levou à implementação da vinculação parte do salário dos/as professores/as a resultados obtidos pelos 
alunos/as e pelas escolas/as, desconsiderando-se as questões estruturais envolvendo verbas para a educação básica e as condições do trabalho docente (EVANGELISTA; VALENTIM, 2013; SILVEIRA; PREVITALI, 2017).

Em paralelo à participação privada na gestão da coisa pública, no artigo 68, a tratar sobre o financiamento da educação, define que "[...] serão recursos públicos destinados à educação" (BRASIL, 1996, p. 24) aqueles provenientes de incentivos fiscais, transferências constitucionais, impostos, recursos previstos em lei. Alerta-se que ao tratar de recursos públicos destinados à educação, a lei não estabelece que seja para a educação pública, o que deixa aberto o caminho para ações de interesses de grupos empresariais em tomar para si fatia do financiamento público (KENJI, 2018).

Para Zanetti ([s.d.]), a LDB 9.394/1996 (BRASIL, 1996), mesmo contendo avanços, ainda ficou aquém daquilo que foi amplamente discutido em fóruns e organizações de classe em defesa da educação pública para todos e de qualidade socialmente referenciada, com a aprovação do projeto substitutivo Darcy Ribeiro, pela alegação de que o projeto em tramitação e que abordava anseios mais amplos da classe docente continha inconstitucionalidades. Segundo a autora, a forte presença de organismos internacionais como Banco Mundial e as aspirações dos neoliberais, cooptaram o processo educacional para formação de força de trabalhado com vistas à manutenção da ordem vigente.

Também Brzezinski (2010) argumenta nesse sentido e afirma que a LDB contém avanços mínimos ao ter aprovado aspirações de especialistas de escritório, subservientes aos interesses de mercado e, ao mesmo tempo, golpeia ideologicamente a sociedade civil organizada, impedindo-a de acompanhar na esfera consultiva os desdobramentos da lei e considerando inconstitucional projeto que propunha criar um Fórum Nacional para discutir e elaborar políticas educacionais ao Conselho Nacional de Educação.

\section{As Diretrizes para Formação Docente a partir do governo Temer}

Considerando-se as Diretrizes Curriculares Nacionais para a Formação Inicial de Professores para a Educação Básica e Base Nacional Comum para a Formação Inicial de Professores da Educação Básica (BNC-Formação), dada pela resolução CNE/CP No: 2/2019, de 20/12/2019, pode-se dizer que as dificuldades já se apresentaram na composição do próprio Conselho Nacional de Educação (CNE). O CNE é um órgão de assessoramento do Ministério da Educação (MEC), responsável por propor políticas públicas na educação. Os pareceres do conselho são submetidos ao ministro, que pode aprovar ou vetar parte das orientações. Ao todo são 24 membros, com mandato de quatro anos, podendo ser prorrogado por mais dois. 
Com o processo de impedimento da presidenta Dilma Rousseff, o interino Michel Temer, torna sem efeito no dia 27 de junho de 2016 o decreto publicado no Diário Oficial da União do dia 11 de maio de 2016 que tratava da designação dos membros do Conselho Nacional, entre eles quatro conselheiros da Câmara da Educação Básica e a três da Câmara da Educação Superior, vinculados às entidades de representação e defesa da categoria docente e à universidade pública. Entre os conselheiros indicados por Dilma estavam, Maria Izabel Azevedo Noronha, presidenta do Sindicato dos Professores do Ensino Oficial do Estado de São Paulo (Apeoesp); Maria Lúcia Cavalli Neder, a ex-diretora da Associação Nacional dos Dirigentes das Instituições Federais de Ensino Superior (Andifes); Antonio Ibañes Ruiz, ex-reitor da Universidade de Brasília (UnB); e Luiz Fernandes Dourado, que dirigiu a Associação Nacional de Pós-Graduação e Pesquisa em Educação (Anped).

A Base Nacional Curricular BNC-Formação (BRASIL, 2019) está proposta para o desenvolvimento do sistema de ensino no Brasil em consonância à BNCC (2018) (Base Nacional Comum Curricular) para a educação básica, de modo a permitir que os itinerários formativos nas escolas tenham similitude aos itinerários formativos dos docentes. Por meio do parecer CNE/CP No: 2/2019 (BRASIL, 2019), estabelece-se que todos os cursos de licenciatura “[...] serão organizados em três Grupos, com carga horária total de, no mínimo, 3.200 (três mil e duzentas) horas, devendo considerar o desenvolvimento das competências profissionais previstas na BNC-Formação.” (BRASIL, 2019, p. 23), ante ao papel segundo o qual os professores "[...] devem desenvolver um conjunto de competências profissionais que os qualifiquem para colocar em prática as dez competências gerais, bem como as aprendizagens essenciais previstas na BNCC.” (BRASIL, 2019, p. 1), visando oferecer educação integral - não é tempo integral - para todos os alunos, primando pela educação de qualidade e superação das desigualdades educacionais.

Neste sentido, alinhada às diretrizes da BNCC, a BNC-Formação estabelece como competências profissionais, competências específicas e competências gerais. Estas competências devem ser a base orientadora para que as IES (Instituições de Ensino Superior) organizem seus Projetos Políticos de Curso e estabeleçam as estratégias para a oferta do ensino, num prazo de até dois anos e, para as instituições que já se adequaram às diretrizes de 2015, prazo de até três anos, a contar da data de publicação das atuais diretrizes, 22 de dezembro de 2019.

Salienta-se ainda que as 3.200 (três mil e duzentas) horas para os cursos de licenciaturas, devem ser articuladas em três grupos na seguinte estrutura:

- Grupo I: 800 (oitocentas) horas para a base comum que compreende os conhecimentos científicos, educacionais e pedagógicos e fundamen- 
tam a educação e suas articulações com os sistemas, escolas e práticas educacionais.

- Grupo II: 1.600 (mil e seiscentas) horas para a aprendizagem dos conteúdos específicos das áreas, componentes, unidades temáticas e objetos de conhecimento da BNCC e para o domínio pedagógico desses conteúdos.

- Grupo III: 800 (oitocentas) horas para a prática pedagógica com a seguinte distribuição: 400 (quatrocentas) horas de estágio e 400 (quatrocentas) horas para os componentes curriculares dos Grupos I e II, das quais:

- 400 (quatrocentas) horas de estágio supervisionado, em situação real de trabalho em escola, segundo o Projeto Pedagógico do Curso (PPC) da instituição formadora;

- 400 (quatrocentas) horas de práticas nos componentes curriculares dos Grupos I e II, distribuídas ao longo do curso, desde o seu início, segundo o PPC da instituição formadora (BRASIL, 2019, s/p).

Considerando-se o que o texto expõe, tem-se que não se trata de 3.200 (três mil e duzentas) horas, mas sim 4.000 (quatro mil) horas e, em termos de avanços para a formação docente seria muito positivo, mas é só o que parece. No grupo I, parte comum, composto de 800 (oitocentas) horas, as IES devem organizar seus sistemas de ensino para que este grupo contemple as três competências específicas - conhecimento profissional, prática profissional e engajamento profissional - " [...] segundo as competências e habilidades da BNCC da Educação Básica para as etapas da Educação Infantil, do Ensino Fundamental e do Ensino Médio.” (BRASIL, 2019, p. 23).

Este primeiro grupo está dividido em treze subgrupos, devendo comtemplar: currículo e seus marcos legais; didática e seus fundamentos; metodologias e práticas de ensino; gestão escolar; marcos legais e conceitos básicos da Educação Especial; interpretação e utilização de indicadores e informações das avaliações de desempenho; desenvolvimento acadêmico e profissional; conhecimento da cultura da escola; fundamentos históricos, filosóficos e sociológicos e função social do/a professor/a; vertentes teóricas do processo de aprendizagem; conhecimento da relação ensino aprendizagem e sistema educacional brasileiro; e, concepção sociocultural dos contextos de vivências educativas dos alunos (BRASIL, 2019).

O grupo II, voltado para o aprofundamento, composto de 1.600 (mil e seiscentas) deve abranger a todas as etapas da educação básica, está dividido em três grandes subgrupos, os quais devem atender a dez orientações gerais, e as específicas de cada subgrupo.

O subgrupo II-I é voltado a cursos de formação de professores/as multidisciplinares da educação infantil, nos quais, englobando as 1.600 (mil e seiscentas) horas, deve contemplar: organização da educação infantil nas 
creches e pré-escolas; particularidades de aprendizagem da educação infantil; planejamento, avaliação e propostas pedagógicas; conteúdos da BNCCEducação Básica; e, competências gerais.

O subgrupo II-II é voltado para a formação de professores/as multidisciplinares dos anos iniciais do Ensino Fundamental, em que nas 1.600 (mil e seiscentas) horas, deve contemplar os componentes curriculares estabelecidos pela BNCC e "[...] devem ainda propiciar o aprendizado da dimensão prática do conhecimento e o desenvolvimento de competências e habilidades equivalentes àquelas que a BNCC prevê para os estudantes da Educação Básica" (BRASIL, 2019, p. 26), como um todo e seus objetos de conhecimento e unidades temáticas, em particular.

No subgrupo II-III, voltado para formação de professores/as nos anos finais do Ensino Fundamental, e do Ensino Médio, as 1.600 (mil e seiscentas) horas devem abranger competências e habilidades ao longo de todo ciclo contemplado na educação básica prevista pela BNCC, envolvendo objetos de conhecimento, conteúdos e unidades temáticas. Segue-se que, demonstrando uma intrínseca relação à proposta da BNCC (2018) de oferta do novo ensino médio, a formação de professores/as para esta etapa da formação já se propõe para atuarem nos ciclos formativos.

As licenciaturas que se destinam à docência, nos anos finais do Ensino Fundamental, e no Ensino Médio, centradas no desenvolvimento de saberes específicos, podem ser ofertadas, de acordo com a organização curricular, em componentes curriculares, componentes interdisciplinares ou áreas de estudos, nos termos do Projeto Pedagógico do Curso (PPC), de forma que favoreçam a compreensão das possibilidades de flexibilização curricular e seus impactos nas etapas da Educação Básica. (BRASIL, 2019, p. 26).

No grupo III, dedicado à parte prática, composto de 800 (oitocentas) horas, está dividida em dois subgrupos de 400 (quatrocentas) horas, dedicadas para a prática pedagógica, articuladas aos componentes curriculares correlacionados desde o primeiro ano de estudo, contemplando o grupo I e II e que englobe os aspectos a seguir: formalização efetiva entre a instituição formadora e a instituição conveniada - não fica estabelecido se esta formalização será feita pelo aluno ou pela instituição formadora -; acompanhamento de docente da instituição formadora e da instituição de campo da prática pedagógica; a prática pedagógica deve preparar o discente para a realização do estágio, de modo que esta the proporcione acompanhamento de todos os processos praticados em sala e na gestão da unidade escolar; registro do planejamento de aula, avaliação e do conhecimento de conteúdo em portfólio que possibilite compilação e comprovação das 
aprendizagens; práticas de planejamento didático, ministração de aulas, que evidenciem a aprendizagem dos alunos e das devolutivas do professor; e, por fim, quando o ensino for na modalidade a distância, as 800 (oitocentas) horas devem ser cumpridas presencialmente.

Antes da análise da distribuição da carga horária, faz-se necessário observar o seguinte dado. O $\int 3^{\circ}$ do art. 62 da LDB incluído pela lei $\mathrm{n}^{\circ}$ 12.056, de 2009, estabelece que "[...] a formação inicial de profissionais de magistério dará preferência ao ensino presencial, subsidiariamente fazendo uso de recursos e tecnologias de educação a distância" (BRASIL, 1996, s/p), ao qual acrescemos redação da análise inicial de conjuntura feita pela equipe bicameral do Conselho Nacional, a "[...] conversão em ritmo acelerado da oferta de cursos presenciais em cursos a distância, e o excesso de instituições que oferecem esses cursos nessa modalidade." (BRASIL, 2019, p. 6) representam desafios para o campo da formação inicial, com destaque para os cursos de licenciaturas e instituições privadas de ensino.

Com relação à educação à distância, SILVA JR (2003) aponta seu caráter de "instrumentalização" e "pseudoformação". Para ele, a prática instrucional e relacional para diferentes sujeitos no processo ensinoaprendizagem à distância implica ao sujeito - discente - uma posição passiva na construção do conhecimento, em que a tensão, a contradição e o conflito, intrínsecos nos processos de formação, são secundarizados pela distância relacional. Para o autor, "[...] A prática escolar deve ser presencial se o objetivo for não somente a instrumentalização do ser humano, mas a elevação de sua condição de ser" SILVA JR (2003, p. 5).

Nas Diretrizes Curriculares Nacionais (BRASIL, 2015), a carga horária para as licenciaturas se dava da seguinte forma, num total de 3.200 (três mil e duzentas) horas. Estágio de 400 (quatrocentas) horas, 400 (quatrocentas) horas de prática como componente curricular, 200 (duzentas) horas na área de interesse do aluno e 2.200 (duas mil e duzentas) horas de conteúdos específicos. Dessa forma, o total geral de carga horária permanece o mesmo, porém sua divisão merece ponderações. Analisando-se o grupo I das novas diretrizes, a prática autorizada pelo Conselho Nacional é de que todos os cursos de licenciatura de uma instituição, indiscriminadamente, tenham 800 (oitocentas) horas de atividade em comum.

De modo geral, isto pode permitir às instituições que ofertam ensino presencial incluir uma grade comum, ou a junção de turmas, levando à superlotação de salas, além de sobre carga de trabalho para professores/as, mecanismo para redução de despesas e também de adoecimento dos/as profissionais. Nas instituições públicas, constrangidas por reduções orçamentárias, pode-se apresentar também uma tendência de também redução de custos, com composição de quadros de professores/as de conhecimentos 
gerais comuns a todas as licenciaturas, além de turmas com número maior de alunos/as.

No caso das instituições que ofertam ensino à distância e, conforme INEP (2018), a quantidade dos alunos/as de cursos de licenciaturas é majoritariamente maior nesta modalidade de ensino na rede privada, tem-se um dos melhores cenários, sobretudo para os grandes grupos educacionais privados posto que, com uso de vídeo e material de um único professor/a por disciplina, pode-se alcançar centenas de polos e milhares de alunos/as de uma única vez, propiciando formação em massa. Cabe lembrar que as instituições públicas e de representação dos profissionais da educação tem sido preterida na composição da comissão do CNE, privilegiando-se, portanto, nomes ligados às instituições privadas e aos grandes grupos educacionais.

As diretrizes (BRASIL, 2015) destinavam carga horária de 2.200 (duas mil e duzentos) horas para formação específica, enquanto que na atual conjuntura será obrigatório o mínimo de 1.600 (mil e seiscentas) horas, resultando em 600 (seiscentas) horas a menos para a parte teórica e específica, evidenciando-se com isso a primazia das diretrizes para a prática em detrimento da carga teórica uma vez que o tempo de formação permanece o mesmo (em média 4 anos). Para Gatti (2019), faz-se necessário "[...] repensar as propostas imediatistas e programas de formação rápida e em modalidades de educação a distância que não têm contribuído para aumentar a sua qualidade" (GATTI, 2019 , p. 315), movimento este na contramão ao que se descortina com a BNCFormação.

No que se refere à parte prática e do estágio supervisionado, composto de 800 (oitocentas) horas, pode-se observar avanços positivos uma vez que a coparticipação do licenciando junto ao professor regente e participação na dinâmica da escola privilegiam maior abrangência de concepção da realidade escolar e das práticas de ensino. Contudo, há que se considerar os mecanismos que as instituições formadoras utilizarão para condução deste processo, dada a predominância da formação em massa nas instituições privadas em exponencial crescimento do ensino a distância e o modo como será tratado este processo formativo. Ademais, a diretrizes estabelecem um próximo acompanhamento de professor/a no campo de estágio e isto não implica em somente assinar uma ficha no final de expediente, há que se ter dedicação. Será mais uma sobrecarga atribuída ao/à professor/a no chão da escola sem a devida remuneração? No Quadro 1 apresenta-se um comparativo entre as Diretrizes Curriculares para a formação de professores publicada em 2015 e em 2019. 
Quadro 1 - Diretrizes Curriculares para a Formação de Professores/as em 2015 e 2019

\begin{tabular}{|c|c|}
\hline Diretrizes (BRASIL, 2015) & Diretrizes (BRASIL, 2019) \\
\hline $\begin{array}{l}\text { Cursos de Segunda licenciatura com } \\
\text { carga horária mínima de } 800 \text { a } 1.200 \text {. Há } \\
\text { exigência de estágio supervisionado de } \\
\text { no mínimo } 300 \text { horas constando no } \\
\text { cômputo total. }\end{array}$ & $\begin{array}{l}\text { Cursos de Segunda licenciatura com } \\
\text { carga horária mínima variável de } 560 \text { a } \\
\text { 760. Não há exigência de estágio } \\
\text { supervisionado. }\end{array}$ \\
\hline $\begin{array}{l}\text { No mínimo } 1.200 \text { horas se a segunda } \\
\text { licenciatura corresponder a área diversa } \\
\text { da formação original; no mínimo } 800 \\
\text { horas se a segunda licenciatura } \\
\text { corresponder a mesma área da formação } \\
\text { original. } 300 \text { horas de estágio, como } \\
\text { parte do cômputo geral. }\end{array}$ & $\begin{array}{l}\text { No mínimo } 560 \text { horas se a segunda } \\
\text { licenciatura corresponder a área diversa } \\
\text { da formação original; no mínimo } 360 \\
\text { horas se a segunda licenciatura } \\
\text { corresponder a mesma área da formação } \\
\text { original, mais } 200 \text { horas para prática } \\
\text { pedagógica para ambos os casos. }\end{array}$ \\
\hline $\begin{array}{l}\text { Formação pedagógica para graduados } \\
\text { não licenciados. Carga horária mínima } \\
\text { variável de } 1.000 \text { a } 1.400 \text { horas } \\
\text { No mínimo } 1.000 \text { horas quando a } \\
\text { formação pedagógica pertencer à } \\
\text { mesma área do curso de origem. No } \\
\text { mínimo } 1.400 \text { horas quando não } \\
\text { pertencer à mesma área do curso de } \\
\text { origem. } 300 \text { horas de estágio para } \\
\text { ambos e } 200 \text { de atividade teórica prática. }\end{array}$ & $\begin{array}{l}\text { Formação pedagógica para graduados } \\
\text { não licenciados. Carga horária de } 760 \\
\text { horas, sendo } 360 \text { para competências } \\
\text { profissionais e } 400 \text { para prática } \\
\text { pedagógica. } \\
\text { Não há distinção entre graduados } \\
\text { licenciados e não licenciados. Não há } \\
\text { exigência de estágio supervisionado. }\end{array}$ \\
\hline
\end{tabular}

Fonte: Elaborado pelos autores.

Constata-se que na formação pedagógica para graduados não licenciados as exigências são idênticas, independentemente do curso de origem. Suponha-se que um bacharel em história e um tecnólogo de Recursos Humanos queiram fazer licenciatura em história, os requisitos são os mesmos. As diretrizes (BRASIL, 2019), neste caso, representam retrocessos para o processo de formação de professores/as, estando plenamente na contramão da propagandeada qualidade para a formação inicial de professores da educação básica.

A formação pedagógica para graduados não licenciados tem um incremento diferencial no quesito precariedade. Este nicho de formação se propõe a tentar superar o déficit histórico de professores/as habilitados/as nas respectivas áreas de atuação. Ao compor o itinerário do curso, o aluno recebe o título de licenciado e poderá atuar em disciplinas do currículo que integram os quatro últimos anos do ensino fundamental, no ensino médio e na educação profissional em nível médio. Note-se que, num curto espaço de tempo, pois as 
diretrizes não estabelecem o prazo mínimo, este nível de formação pode ser cumprido, em um semestre, representando um novo profissional "apto" a atuar no ensino segundo as diretrizes (BRASIL, 2019).

Esta modalidade, além de formação em massa, gera efeitos nocivos para a educação pública. As mudanças são feitas em nome da qualidade da educação, cabendo-se questionar qual qualidade, pois, colocar-se-á no mercado profissionais com condições duvidosas de domínio de seu campo de saber, a atuarem de modo especial com contrato de trabalho precário, por meio de designações, em escolas com menos recursos, localizadas especialmente nas periferias, atendendo estudantes da classe trabalhadora em condições de maior vulnerabilidade. Nesse contexto, o que se proporciona em considerável escala é a composição de exércitos de reserva, conforme Marx (2013), contribuindo para pressionar a remuneração do/a docente para baixo, favorecendo o desrespeito ao cumprimento do piso salarial em nome da sustentabilidade financeira da instituição privada ou mesmo pública. Nesse sentido, as diretrizes (BRASIL, 2019) representam um vilipêndio para a educação básica pública e para os/as professores/as e, portanto, não asseguram nem formação nem educação de qualidade, mas sim, a redução dos custos do trabalho e da educação.

Segundo Gatti (2019), importa se considerar a formação de professores sob outro prisma, atentando-se para propiciar sólida formação e condições de trabalho adequadas para o desenvolvimento profissional e de carreira digna, formação coerente e interdisciplinar em correlação aos contextos sociais e culturais que serão campo de atuação dos licenciandos, maior proximidade entre instituições formadoras e escolas e rigor na realização e avaliação de estágios, além de efetivar sistema de apoio aos professores orientadores de estágios nas escolas, e fomentar projetos interdisciplinares e integrados na oferta das disciplinas.

Tendo como base o Censo da Educação Superior de 2018, 1.264,288 (um milhão, duzentos e sessenta e quatro mil, duzentos e oitenta e oito) alunos concluíram educação superior de graduação no Brasil, destes, 79,5\% em instituições privadas e, 20,5 em instituições públicas. Conforme Gráfico 1, de acordo com o grau acadêmico, há predominância nos cursos de bacharelado, com 63,4\%, seguido de licenciatura com 19,8\% e, tecnólogo com 16,8\%. Se juntarmos os dois cursos, cuja formação não é para a prática de ensino, temos uma proporção de $80,2 \%$ para $19,8 \%$. 
Gráfico 1 - Concluintes em cursos de graduação, por grau acadêmico, Brasil, 2008-2018.

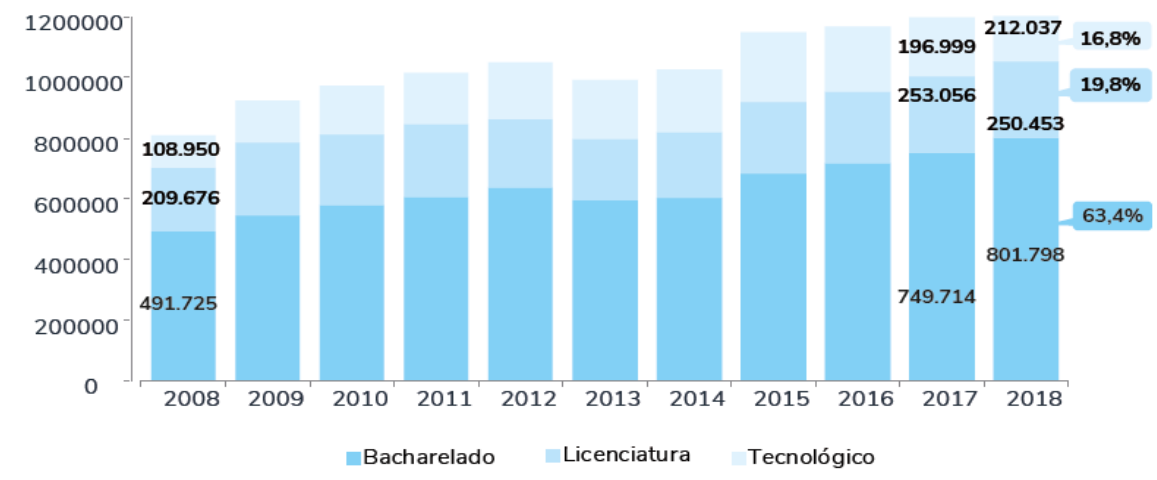

Fonte: (INEP, 2018, p. 33)

Ao considerar-se o número de matrículas em cursos superiores no Brasil no intervalo de 2008 a 2018 (Gráfico 2), verifica-se que continua havendo predominância de interesse para cursos que não tenham como campo de trabalho o ensino. Os bacharelados representam 67,6\% do número de matrículas, as licenciaturas 19,4\% e, os tecnólogos, 13\%.

Gráfico 2 - Matrículas em cursos de graduação por grau acadêmico, Brasil, 2008-2018.

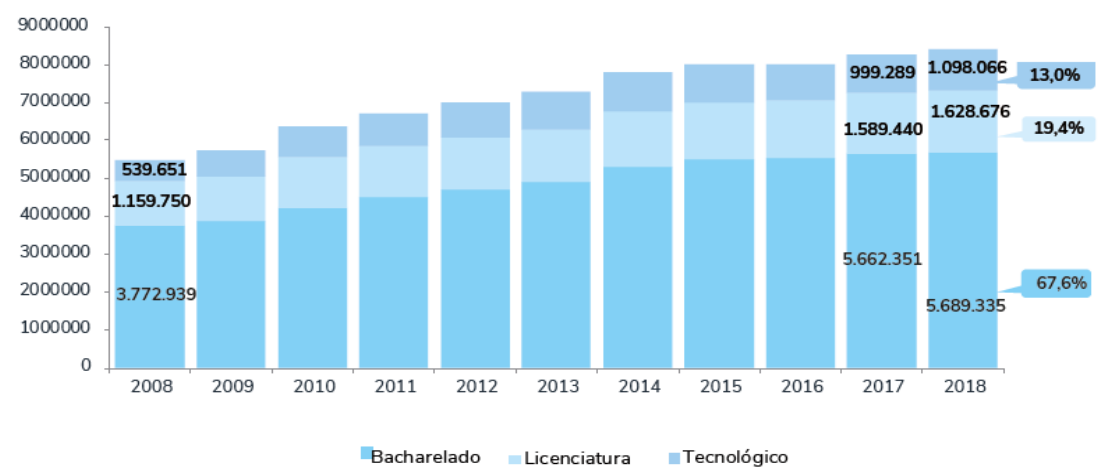

Fonte: (INEP, 2018, p. 25).

De acordo com o Quadro 2, houve aumento no número de matrículas e conclusões por grau acadêmico no intervalo de 2008-2018, resultado este esperado. Ao observar-se os percentuais de aumento de conclusões/matrículas, identifica-se uma linearidade entre os cursos bacharéis e tecnólogos. Contudo, 
há uma quebra na curva do nível nas licenciaturas, o que representa maior desistência dos alunos deste nicho de formação. $\mathrm{O}$ fenômeno observado pode ser corroborado pelas pesquisas de Gatti (2019), que, ao apresentar panorama de cursos de licenciatura, destaca que na primeira década do século XXI houve aumento expressivo no número de matrículas, porém, "[...] na segunda década o crescimento arrefece nitidamente, tanto no cômputo geral das licenciaturas, quanto nos cursos que preparam docentes para os anos iniciais da educação básica" (GATTI, 2019, p. 306).

Quadro 2: Número Matrículas e Conclusões por Grau Acadêmico e Percentual de Matrículas e Conclusões por Grau Acadêmico, Brasil, 2008-2018.

\begin{tabular}{|l|l|l|}
\hline $\begin{array}{c}\text { Curso por grau } \\
\text { acadêmico }\end{array}$ & $\begin{array}{c}\text { Número de matrículas } \\
\text { em 2008 e em 2018 }\end{array}$ & $\begin{array}{c}\text { Número de conclusões } \\
\text { em 2008 e em 2018 }\end{array}$ \\
\hline Bacharel & $\begin{array}{l}(3.772 .939 / 5.689 .335), \\
\text { aumento de 50\% }\end{array}$ & $\begin{array}{l}(491.725 / 801.798), \\
\text { aumento de 63,1\% }\end{array}$ \\
\hline Tecnólogo & $\begin{array}{l}(539.651 / 1.098 .066), \\
\text { aumento de } 103 \%\end{array}$ & $\begin{array}{l}(108.950 / 212.037), \\
\text { aumento de } 94,6 \%\end{array}$ \\
\hline Licenciatura & $\begin{array}{l}(1.159 .750 / 1.628 .676) \\
\text { aumento de 40,4\% }\end{array}$ & $\begin{array}{l}(209.676 / 250.453), \\
\text { aumento de 19,4\% }\end{array}$ \\
\hline
\end{tabular}

Fonte: elaboração dos autores com base em sinopses estatísticas do Censup (2018).

Há que se considerar o efeito maléfico das novas diretrizes não somente a organização de estrutura de ensino, mas também para o contexto social mais amplo. A LDB (BRASIL, 1996) abre a possibilidade, no artigo 32, § $4^{\circ}$, que, "[...] para efeito de cumprimento das exigências curriculares do ensino médio, os sistemas de ensino poderão reconhecer competências e firmar convênios com instituições de educação a distância com notório reconhecimento" (BRASIL, 1996, s/p), e acrescenta no artigo 80, “[...] o Poder Público incentivará o desenvolvimento e a veiculação de programas de ensino à distância, em todos os níveis e modalidades de ensino, e de educação continuada" (BRASIL, 1996, s/p). Neste sentido, as diretrizes de 2019 (BRASIL, 2019) trazem como exigência para a formação de professores/as na parte comum do currículo, em uma das dez competências gerais, a obrigatoriedade do domínio das novas tecnologias informacionais-digitais.

Compreender, utilizar e criar tecnologias digitais de informação e comunicação de forma crítica, significativa, reflexiva e ética nas diversas práticas docentes, como recurso pedagógico e como ferramenta de formação, para comunicar, acessar e disseminar informações, produzir conhecimentos, resolver problemas e potencializar as aprendizagens. (BRASIL, 2019, p. 17). 
Assim, o discurso inicial do CNE na proposição das Diretrizes ancorase no artigo 23 da LDB e enfatiza que a educação básica poderá ter "[...] forma diversa de organização, sempre que o interesse do processo de aprendizagem assim o recomendar" (BRASIL, 1996, s/p), destacando que a principal atribuição do profissional do magistério é zelar pela aprendizagem dos alunos, correlacionado ao argumento da pouca representatividade dos resultados de avaliações de larga escala no Brasil, tendo como referência os anos entre 2010 e 2017. Destaca ainda que o Ideb está estacionário, por isso "[...] a melhoria no desempenho desses indicadores, exigem a contribuição dos professores, além do incremento das políticas públicas para a área" (BRASIL, 2019, p. 5). Esse discurso busca legitimar a introdução de novos recursos, especialmente aqueles vinculados às novas tecnologias, para a aprendizagem dos alunos ante aos insignificantes resultados.

Portanto, incremento de tecnologias informacionais e de comunicação na formação dos novos/as licenciandos/as está para além do aspecto formação e capacitação para construção de conhecimentos. Ele vai de encontro a um projeto para a educação básica no país ${ }^{1}$, de modo a preparar o terreno para, num futuro a curto ou médio prazo, introduzir o ensino à distância também na educação básica, com efetiva participação do empresariado do setor educacional (FAGIANI, 2018).

\section{Considerações Finais}

A Lei de Diretrizes e Base (LDB) 9.394/1996 (BRASIL, 1996), representou avanços substanciais ao estabelecer pelo artigo 62 a formação em nível superior para atuação na educação básica e, no artigo 67 a definição de ingresso na carreira pública exclusivo por concurso público de provas e títulos, piso salarial, condições adequadas para o trabalho, progressão funcional, além de definir exigências para as instituições de nível superior para a oferta de ensino, avaliações periódicas, garantia de padrões mínimos de qualidade, entre outros. Entretanto, no campo das lutas sociais para efetiva sua implementação, pouco se avançou.

Sob o neoliberalismo e a NGP, as reformas educacionais para a educação básica tenderam à precarização da formação docente, impondo uma formação mais técnica e aligeirada, sob condições e relações de trabalho instáveis, privatizadas e terceirizadas que não asseguram o desenvolvimento profissional, levando à desvalorização da profissão e ao abandono da docência.

\footnotetext{
${ }^{1}$ Fala do ministro Mendonça Filho, em 08 de julho de 2016. "Eu ouso aqui fazer um chamamento ao empresariado brasileiro para juntos, nos mobilizarmos, a fim de fortalecer a base educacional do país, melhorando a qualidade do ensino." Disponível em: http://portal.mec.gov.br/component/content/article?id=37681. Acesso em: 09 abr. 2019.
} 
Sob tais condições, não causa estranhamento os resultados abaixo do esperado nas avaliações de larga escala, pois estas demandam minimamente condições e valorização do trabalho docente, proporção aluno/a professor/a adequada e infraestrutura, com as quais os resultados seriam consequência do processo e não meramente a meta. As estratégias de formação em massa e aligeirada nos cursos de licenciatura e formação pedagógica não produziram os resultados esperados em termos de matrículas e conclusões em curso conforme demonstrado a partir do INEP (2018), as quais não acompanharam os resultados de cursos dos graus de bacharel e tecnólogo.

Destaca-se que as mudanças não se fazem de forma linear e sem resistências da categoria docente e da sociedade civil, mas tendem a privilegiar o que se objetiva pela classe dominante, por um lado, o lucro imediato na prestação de serviços e, por outro, a manutenção da segregação de classes.

Não será motivo de espanto se as próximas medidas no âmbito das políticas educacionais estiverem assentadas na educação à distância para parte da educação básica montada, estruturada e ofertada em parceria com a iniciativa privada em nome da chamada eficiência e da eficácia para os cofres públicos.

\section{Referências}

ANTUNES, R. O Privilégio da Servidão. São Paulo: Boitempo, 2018.

BRZEZINSKI, I. Tramitação e desdobramentos da LDB/1996: embates entre projetos antagônicos de sociedade e de educação. Trabalho, Educação e Saúde, Rio de Janeiro, v. 8, n. 2, p. 185-206, jul./out. 2010.

BRASIL. Lei $\mathrm{n}^{\circ} \mathbf{9 . 3 9 4}$, de 20 de dezembro de 1996. Estabelece as diretrizes e bases da educação nacional. Brasília, DF: Ministério da Educação, 1996. Disponível em: http://www.planalto.gov.br/ccivil_03/leis/19394.htm. Acesso em: 08 abr. 2020.

BRASIL. Ministério da Educação. Resolução CNE/CEB n. 2, de 16 de junho de 1997. Dispõe sobre os programas especiais de formação pedagógica de docentes para as disciplinas do currículo do ensino fundamental, do ensino médio e da educação profissional em nível médio. Brasília, DF: Ministério da Educação, 1997. Disponível em: http://portal.mec.gov.br/setec/arquivos/ pdf/RCNE_CEB02_97.pdf. Acesso em: 09 abr. 2020. 
BRASIL. Conselho Nacional de Educação. Conselho Pleno. Parecer n. 9, de 8 de maio de 2001. Dispõe sobre as Diretrizes Nacionais para a Formação de Professores da Educação Básica, em nível superior, curso de licenciatura, de graduação plena. Brasília, DF: Conselho Nacional de Educação, 2001.

Disponível em http://portal.mec.gov.br/cne/arquivos/pdf/009.pdf. Acesso em: 10 jul. 2021.

BRASIL. Ministério da Educação. Conselho Nacional de Educação. Conselho Pleno. Resolução n. 2, de $\mathbf{1}^{\mathbf{0}}$ de julho de 2015. Define as Diretrizes Curriculares Nacionais para a formação inicial em nível superior (cursos de licenciatura, cursos de formação pedagógica para graduados e cursos de segunda licenciatura) e para a formação continuada. Brasília, DF: Ministério da Educação, 2015. Disponível em: http://portal.mec.gov.br/index.php? option $=$ com_docman $\&$-view $=$ download\&alias $=70431$-res-cne-cp-00203072015-pdf\&-category_slug=agosto-2017-pdf\&Itemid=30192. Acesso em: 09 abr. 2020.

BRASIL. Diário Oficial da União. Brasília, DF: Ministério da Educação, 2016. Disponível em: https://www.jusbrasil.com.br/diarios/119193043/dou-secao2-28-06-2016-pg-12. Acesso em: 14 abr. 2020.

BRASIL. Ministério da Educação. Base Nacional Comum Curricular. Brasília, DF: 2018. Disponível em http://basenacionalcomum.mec.gov.br/images/BNCC_EI_EF_110518_versa ofinal_site.pdf. Acesso em 11jul. 2021.

BRASIL. Instituto Nacional de Estudos e Pesquisas Educacionais Anísio Teixeira (Inep). Censo da Educação Superior 2018: notas estatísticas. Brasília, 2019. Disponível em

https://download.inep.gov.br/educacao_superior/censo_superior/documento s/2019/censo_da_educacao_superior_2018-notas_estatisticas.pdf. Acesso em 10 jul. 2021.

BRASIL. Ministério da Educação. Resolução n. 2, de 20 de dezembro de 2019. Define as Diretrizes Curriculares Nacionais para a Formação Inicial de Professores para a Educação Básica e institui a Base Nacional Comum para a Formação Inicial de Professores da Educação Básica (BNC-Formação). Brasília, DF: Ministério da Educação, 2019. Disponível em: http://portal.mec.gov.br/docman/dezembro-2019-pdf/135951-rcp002-19/ file. Acesso em: 09 abr. 2020. 
EVANGELISTA, S. T.; VALENTIM, I. V. L. Remuneração Variável de Professores: controle, culpa e subjetivação. Educação \& Realidade, Porto Alegre, v. 38, n. 3, p. 999-1018, jul./set. 2013. Disponível em: http://www.ufrgs.br/edu_realidade Acesso em: 13 abr. 2020.

FAGIANI, C. C. Brasil e Portugal, qual a formação do trabalhador para o século XXI? Uberlândia: Navegando Publicações, 2018.

GATTI, B. A.; BARRETTTO, E. S. de S.; ANDRÉ, M. E. D. A. de; ALMEIDA, P. C. A. de. Professores do Brasil: novos cenários de formação. Brasília: UNESCO, 2019.

HARVEY, D. O Enigma do Capital. São Paulo: Boitempo. 2011.

HILL, D. O neoliberalismo global, a resistência e a deformação da educação.

Currículo sem Fronteiras, Brasil, v. 3, n. 2, p. 24-59, jul./dez. 2003.

Disponível em:

http://www.curriculosemfronteiras.org/vol3iss2articles/hill.pdf. Acesso em: 12 jun. 2014.

HYPOLITO, Á. L. M. Trabalho Docente e o Novo Plano Nacional de Educação: Valorização, Formação e Condições de Trabalho. Caderno Cedes, Campinas, v. 35, n. 97, p. 517-534, set./dez. 2015. Disponível em: http://www.scielo.br/pdf/ccedes/v35n97/1678-7110-ccedes-35-9700517.pdf . Acesso em: 15 de mar. 2019.

INEP. Censo da educação superior 2018: notas estatísticas. Brasília, DF: Ministério da Educação, 2018. Disponível em: http://portal.inep.gov.br/. Acesso em: 10 abr. 2020.

KENJI, A. Kroton Educacional: 'Em termos de educação pública nunca experimentamos um inimigo com uma força social tão concentrada como esse'. REVISTA IHU ON-LINE, , , , 27 abr. 2018. Entrevista concedida a André Antunes do Portal EPSJV/Fiocruz. Disponível em:

http://www.ihu.unisinos.br/188-noticias/noticias-2018/578444-krotoneducacional-em-termos-de-educacao-publica-nunca-experimentamos-uminimigo-com-uma-forca-social-tao-concentrada-como-esse. Acesso em: 12 jan. 2020.

MARX, K. O Capital. Livro 1. São Paulo: Boitempo. 2013.

PEREIRA, L. D. S. Crise nas licenciaturas e a luta pela educação no Brasil. Uberlândia: Navegando, 2018.

PREVITALI, F. S.; FAGIANI, C. C. Estado de Bem-Estar Social, Neoliberalismo e Estado Gestor: aproximações globais. In: LUCENA, Carlos; 
PREVITALI, F. S.; LUCENA, L. (org.). A Crise da Democracia Brasileira. Uberlândia: Ed. Navegando, 2017. p. 79-98.

PREVITALI, F. S.; FAGIANI, C. C. Trabalho Digital e Educação No Brasil. In: ANTUNES, R. (org.). Uberização, trabalho digital e Indústria 4.0. São Paulo: Boitempo. 2020. p. 217 -236.

NEWMAN, J.; CLARKE, J. Gerencialismo. Educ. Real, Porto Alegre, v. 37, n. 2, p. 353-381, 2012. Disponível em: http://dx.doi.org/10.1590/S217562362012000200003. Acesso em: 14 jun. 2014.

OLIVEIRA, D. A. de. Nova Gestão Pública e Governos DemocráticoPopulares: contradições entre a Busca da Eficiência e a ampliação do direito à Educação. Educ. Soc., Campinas, v. 36, n. 132, p. 625-646, jul./set., 2015.

Disponível em: http://www.scielo.br/pdf/es/v36n132/1678-4626-es-36-13200625.pdf. Acesso em: 10 nov. 2015.

SAVIANI, D. Pedagogia Histórico-Crítica, quadragésimo ano. Campinas: Autores Associados, 2019.

SILVA JÚNIOR, J. dos R. Reformas do Estado e da educação e as políticas públicas para a formação de professores a distância: implicações políticas e teóricas. Revista Brasileira de Educação, Rio de Janeiro, n. 24, set./out./nov./dez. 2003. p. 78-94. Disponível em https://www.scielo.br/j/rbedu/a/69y5kKWzfnP8Y5GsxKTPr3q/? lang $=$ pt\&format $=$ pdf. Acesso em 10 jul. 2021.

SILVEIRA, E. R. M. da; PREVITALI, F. S. Trabalho Docente e Políticas Educacionais: um estudo sobre o Controle do trabalho docente na rede estadual de ensino de Minas Gerais em Uberlândia - a partir de 2003. Revista Inova Ciência Tecnologia, v. 3, n. 2, p. 64-72, jul./dez. 2017. Disponível em: http://periodicos.iftm.edu.br/index.php/inova/article/view/244. Acesso em: 12 fev. 2018.

ZANETTI, M. A. Política educacional e LDB: algumas reflexões. [s.d.]. Disponível em: http://www.ifil.org/Biblioteca/zanetti.htm. Acesso em: 15 mar. 2020.

\section{Agradecimentos}

Agradecemos a todos e todas os/as colegas do Grupo de Pesquisa Trabalho Educação e Sociedade - GPTES pelo profícuo debate e considerações sobre esse trabalho. 